\title{
TEMPO DE AQUECIMENTO DO LEITE E A CONTAGEM DE CÉLULAS SOMÁTICAS E PORCENTAGENS DE GORDURA E PROTEÍNA
}

\author{
Alfredo Ribeiro Pereira ${ }^{1 *}$; Cristiane Antonia de Oliveira²; Paulo Fernando Machado²; Gabriel \\ Adrián Sarriés ${ }^{3}$ \\ ${ }^{1}$ Pós-Graduando do Depto. de Produção Animal - ESALQ/USP. \\ ${ }^{2}$ Depto. de Produção Animal - ESALQ/USP, C.P. 9 - CEP: 13418-900 - Piracicaba, SP. \\ ${ }^{3}$ Depto. de Ciências Exatas - ESALQ/USP. \\ *e-mail: alrperei@carpa.ciagri.usp.br
}

RESUMO: Com o objetivo de se determinar o efeito do tempo de aquecimento de amostras de leite sobre sua contagem de células somáticas (CCS), porcentagens de gordura e proteína foi realizado um experimento com delineamento em blocos casualizados (10 blocos com 9 parcelas). Os tratamentos foram aquecimento em banho-maria a $40{ }^{\circ} \mathrm{C}$ nos tempos de 10, 20, 30, 40, 50, 60, 70, 80, e 90 minutos. As amostras de leite foram analisadas nos equipamentos Somacount 300 (CCS) e Bentley 2000 (\% de gordura e proteína). Os resultados obtidos foram analisados através de análise de variância, teste $F$ e análise de regressão. A CCS e a \% de proteína não sofreram alteração pelo tempo de aquecimento. A análise de variância da \% de gordura detectou efeito do tempo de aquecimento, mas a análise de regressão não indicou nenhuma regressão possível, sendo que esta variação provavelmente foi ao acaso. Os dados permitem concluir que o tempo de aquecimento em banho-maria a $40^{\circ} \mathrm{C}$ não é um fator que afete a CCS ou as porcentagens de gordura e proteína do leite, viabilizando maior período de manipulação laboratorial das amostras.

Palavras-chave: células somáticas, gordura, proteína, tempo de aquecimento, leite

\section{MILK HEATING TIME AND SOMATIC CELL COUNT AND FAT AND PROTEIN PERCENTAGES}

\begin{abstract}
The effect of the heating time on somatic cell count (SCC), fat and protein in milk samples was evaluated in a completely randomized block experiment with 10 blocks with 9 replicates). Treatments used a double boiler heated to $40^{\circ} \mathrm{C}$ for: 10 (control), 20,30,40,50,60, 70, 80, and 90 minutes. Milk samples were analysed using the fluxometric cytometry (CCS) and infrared absorbance (fat and protein percentage) equipments. Results are discussed using analysis of variance, $F$ test and regression analysis. There were no effects of the heating time for CCS and protein percentage. Analisys of variance indicated a heating time effect on fat percentage, however the regression analysis indicated no suitable regression. It was concluded that the heating time in a double boiler at $40^{\circ} \mathrm{C}$ does not affect $\mathrm{CCS}$ and fat and protein milk percentages, which allows a longer period of laboratory handling.
\end{abstract}

Key words: somatic cell, fat, protein, heating time, milk

\section{INTRODUÇÃO}

A introdução de analisadores automáticos de leite tem permitido 0 desenvolvimento de laboratórios centrais para análise de leite, visando melhorar o manejo do rebanho e viabilizar sistemas de pagamento do leite por qualidade, com a vantagem, em muitos casos, de ter maior rapidez e acurácia na análise dos componentes do leite (Monardes et al. 1996).

Devido a destinação que se dará aos resultados das análise é muito importante que a colheita, o acondicionamento e transporte das amostras até o laboratório, o preparo para análise e a análise propriamente dita sejam corretamente conduzidos para que se obtenha dados confiáveis. 
A operação que toma mais tempo durante o manipulação laboratorial é o aquecimento das amostras que é realizado em banho maria a $40^{\circ} \mathrm{C}$ por 10 minutos. Geralmente durante o aquecimento das amostras o laboratorista executa alguma outra tarefa, inclusive operação da máquina de análise de leite, com o objetivo de melhor utilizar seu tempo, mas muitas vezes ele não consegue finalizar a tarefa antes do termino do tempo de aquecimento, assim as amostras são aquecidas por mais tempo que o padrão.

O objetivo deste trabalho foi verificar o efeito do tempo de aquecimento de amostras de leite em banho-maria sobre suas porcentagens de gordura e proteína e sua contagem de células somáticas (CCS).

\section{MATERIAL E MÉTODOS}

Foram colhidas amostras de leite de 10 vacas que não apresentavam sinais clínicos de mastite. As amostras foram então cuidadosamente homogeneizadas e divididas em 9 subamostras com $60 \mathrm{ml}$ de leite, perfazendose um total de 90 amostras de leite.

O delineamento experimental utilizado foi de blocos casualizados. Assim o leite de cada vaca representou um bloco, e cada subamostra uma parcela.

O modelo matemático utilizado foi $\mathrm{y}_{\mathrm{ij}}=$ $\mu+t_{i}+b_{j}+\varepsilon_{i j}$

onde: $y_{i j}$ é a contagem de células somáticas obtida no bloco (leite) j, pelo efeito do tratamento (tempo de aquecimento) i, sob a ação da variação ao acaso $\varepsilon_{\mathrm{ij}}$ associada a esta amostra;

$\mu$ é uma constante;

$t_{i}$ é o efeito do tratamento i (tempo de aquecimento) da amostra; cada vaca;

$b_{j}$ é o efeito do bloco j, isto é do leite de amostra ij.

$\varepsilon_{\mathrm{ij}}$ é a variação do acaso associada a

As noventa amostras foram aquecidas em banho maria a $40^{\circ} \mathrm{C}$ (Bentley 1995) e a cada 10 minutos foi retirada do banho uma parcela de cada bloco para serem analisadas para contagem de células somáticas, porcentagens de gordura e proteína.

As análises de gordura e proteína foram executadas por absorção infravermelha no equipamento Bentley 2000 (Bentley 1995) e as contagens de células somáticas foram executadas por citometria fluxométrica no equipamento Somacount 300. Este equipamento é baseado na contagem de DNA reagido com corante e iluminado por raio laser (Somacount 1995).

As análises estatísticas foram realizadas no pacote estatístico SAS Institute (1990), utilizando-se do procedimento de modelos lineares gerais (Proc GLM) e o procedimento de regressão (Proc Reg), aplicando-se análise de variância, teste $\mathrm{F}$ e análise de regressão.

\section{RESULTADOS E DISCUSSÃO}

\section{Contagem de Células Somáticas}

Foi realizada análise de variância e foi aplicado o teste $F$ nos dados de contagem de células somáticas como indicado na TABELA 1.

O quadro de análise de variância na

TABELA 1 - Análise de variância e aplicação do teste $\mathrm{F}$ nas contagens de células somáticas do leite.

\begin{tabular}{lcrrr}
\hline C.V. & G.L. & \multicolumn{1}{c}{ S.Q. } & Q.M. & Pr $>$ F \\
\hline TEMPO & 8 & 4597,76 & 574,72 & 0,8512 \\
BLOCOS & 9 & 4035189,82 & 448354,42 & 0,0001 \\
RESÍDUO & 72 & 82530,58 & 1145,88 & \\
\hline TOTAL & 89 & 4122291,16 & & \\
\hline
\end{tabular}

TABELA 1 indica que ocorreu o efeito esperado do bloco, mas não houve efeito do tempo de aquecimento $(P>0,8512)$, isto é a probabilidade de erro ao se afirmar que o tempo de aquecimento possui efeito sobre a CCS é de $85 \%$ sobre a contagem de células somáticas. A ausência de efeito pode também ser visualizada na figura 1 , onde claramente é mostrado pela linha de tendência que é aproximadamente horizontal mostrando nenhuma alteração da CCS ao longo do tempo. Além disso a equação determinada para a CCS em função do tempo de aquecimento apresenta um coeficiente de determinação muito baixo $\left(r^{2}=0,0001\right.$, o que significa que apenas um décimo de milésimo da variação da CCS pode ser explicada pelo tempo de aquecimento).

As moléculas de DNA geralmente desnaturam com o aumento de temperatura, normalmente acima de 80 a $90^{\circ} \mathrm{C}$ (Lehninger et al. 1995). Assim a temperatura utilizada $\left(40^{\circ} \mathrm{C}\right)$ não foi capaz de provocar alterações no DNA que pudessem interferir na contagem de células somáticas realizada pelo equipamento.

O fato do tempo de aquecimento não ter 
sido significativo é de grande importância, pois indica que as amostras permanecem confiáveis e podem ser utilizadas na determinação da CCS mesmo que por algum motivo elas permaneçam por mais tempo que o padrão em aquecimento.

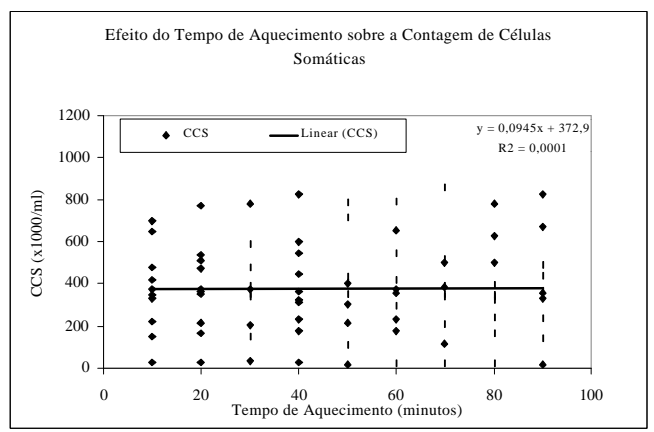

Figura 1 - Efeito do tempo de aquecimento sobre a contagem de células somáticas.

\section{Porcentagem de Gordura}

Foi realizada análise de variância e foi aplicado o teste $\mathrm{F}$ nos dados de porcentagem de gordura como é indicado na TABELA 2.

O quadro de análise de variância na TABELA 2 indica que houve efeito significativo do tempo de aquecimento das amostras sobre a porcentagem de gordura $(P<0,0109)$.

Desse modo foi dado continuidade a análises estatísticas através da utilização da análise de regressão indicada na TABELA 3.

TABELA 2 - Análise de variância e aplicação do teste $\mathrm{F}$ nas porcentagens de gordura do leite.

\begin{tabular}{lcccc}
\hline C.V. & G.L. & S.Q. & Q.M. & $\operatorname{Pr}>$ F \\
\hline TEMPO & 8 & 0,06342889 & 0,00792861 & 0,0109 \\
BLOCOS & 9 & 76,13822333 & 8,45980259 & 0,0001 \\
RESÍDUO & 72 & 0,2092911 & 0,00290175 & \\
\hline TOTAL & 89 & 76,3284900 & & \\
\hline
\end{tabular}

TABELA 3 - Análise de regressão entre o tempo de aquecimento e porcentagens de gordura do leite.

\begin{tabular}{lcccc}
\hline C.V. & G.L. & S.Q. & Q.M. & Pr $>$ F \\
\hline MODELO & 1 & 0,00470 & 0,00470 & 0,9415 \\
RESÍDUO & 88 & 76,41058 & 0,86825 & \\
\hline TOTAL & 89 & 76,41058 & & \\
\hline
\end{tabular}

As regressões linear e quadrática, ao serem analisadas mostraram-se não significativas ( $P>94,15$ e $P>99,73$ ) como pode ser visto no quadro de análise de regressão da TABELA 3 e 4. A figura 2 também indica a não existência de efeito de tempo de aquecimento de amostras de leite sobre sua porcentagem de gordura através da horizontalidade da reta de tendência e através do coeficiente de determinação $\left(r^{2}=0,00006\right.$, significa que 6 centésimos de milésimos da variação da porcentagem de gordura pode ser explicada pela variação do tempo de aquecimento).

O fato de que a análise de variância ter indicado efeito do tempo de aquecimento sobre e a porcentagem de gordura e a análise de regressão não ter sido significativa é explicado pelo fato de que os tempos de aquecimento não diferiram do tempo padrão (10 minutos) com exceção dos tempo de 20 e 70 minutos (teste de Dunnett a $5 \%$ de significância, porém quando realizado a $1 \%$ deixa de ser significativa as diferenças entre as médias), assim a análise de variância detectou diferença, mas por serem pontos dispersos e distantes levou a análise de regressão a não detectar efeito do tempo de aquecimento sobre as porcentagens de gordura.

TABELA 4 - Análise de regressão quadrática entre o tempo de aquecimento e porcentagens de gordura do leite.

\begin{tabular}{lcccc}
\hline C.V. & G.L. & S.Q. & Q.M. & Pr $>$ F \\
\hline MODELO & 2 & 0,00471 & 0,00235 & 0,9973 \\
RESÍDUO & 87 & 76,40587 & 0,87823 & \\
\hline TOTAL & 89 & 76,41058 & & \\
\hline
\end{tabular}

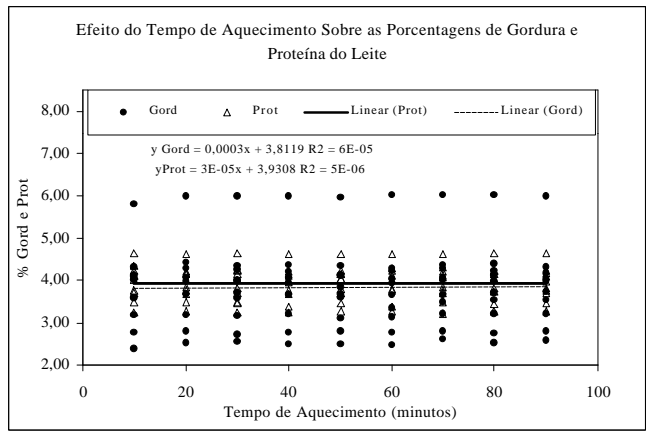

Figura 2 - Efeito do tempo de aquecimento sobre as porcentagens de gordura e proteína do leite. 
Provavelmente a diferença nas porcentagens de gordura do tempo 2 e 7 seja devido a variação ao acaso, ou falha na homogeneização das amostras no momento da análise. Neste ultimo caso a CCS e a porcentagem de proteína não foram afetadas por serem estes componentes mais facilmente homogeneizáveis que a gordura.

\section{Porcentagem de Proteína}

Foi realizada análise de variância e foi aplicado o teste $\mathrm{F}$ nos dados de porcentagem de proteína como é indicado na TABELA 5.

$O$ quadro de análise de variância na TABELA 5 indica que houve o efeito esperado do bloco e houve uma tendência de efeito do tempo de aquecimento das amostras sobre a porcentagem de proteína, mas esta não foi significativa. Esta ausência de efeito do tempo de aquecimento é também visualizada pela figura 2 através da horizontalidade da reta de tendência da porcentagem de proteína e pelo coeficiente de determinação $\left(r^{2}=0,000005\right.$, isto é 5 partes por milhão da variação de proteína pode ser explicada pela variação do tempo de aquecimento.

As proteínas desnaturam quando aquecidas a $40-50^{\circ} \mathrm{C}$ (Lehninger 1981), mas a caseína, que representa $80 \%$ da proteína do leite, é altamente resistente ao calor sendo necessário 12 horas a $100^{\circ} \mathrm{C}$ ou 1 hora a $120^{\circ} \mathrm{C}$ para a sua desnaturação (Oliveira \& Caruso 1996). Novamente a temperatura utilizada não foi suficientemente alta para provocar alterações nas moléculas que pudessem interferir na determinação eletrônica da porcentagem de proteína.

Como na CCS, o tempo de aquecimento não foi significativo para a porcentagem de proteína, e isto é indicativo que as amostras de leite mesmo tendo sido aquecidas por mais tempo que o normal (até 90 minutos) poderão ser utilizadas na determinação da porcentagem de proteína.
TABELA 5 - Análise de variância e aplicação do teste $\mathrm{F}$ nas porcentagens de proteína do leite.

\begin{tabular}{lcrcc}
\hline C.V. & G.L. & S.Q. & Q.M. & $\operatorname{Pr}>$ F \\
\hline TEMPO & 8 & 0,04526222 & 0,00565778 & 0,0611 \\
BLOCOS & 9 & 13,37752889 & 1,48639210 & 0,0001 \\
RESÍDUO & 72 & 0,20567111 & 0,00285654 & \\
\hline TOTAL & 89 & 13,62846222 & & \\
\hline
\end{tabular}

\section{CONCLUSÃO}

$\mathrm{O}$ aquecimento das amostras de leite por até 90 minutos $\left(\mathrm{a} 40^{\circ} \mathrm{C}\right.$ ) não altera a contagem de células somáticas ou porcentagens de gordura e proteína, possibilitando maior período de manipulação laboratorial das amostras.

\section{REFERÊNCIAS BIBLIOGRÁFICAS}

BENTLEY 2000. Operator's manual. Chaska: Bentley Instruments, 1995. 77p.

LEHNINGER, A.L. Biochemistry. 2.ed. New York: Worth Publishers, 1981. 1104p.

LEHNINGER, A.L.; NELSON, D.L.; COX, M.M. Princípios de bioquímica. 2.ed. São Paulo: Savier, 1995. 839p.

MONARDES, H.G.; MOORE, R.K.; CORRIGAN, B.; RIOUX, Y. Preservation and storage mechanism for raw milk samples for use in milk-recording schemes. Journal of Food Protection, v.59, n.2, p.151-154, 1996.

OLIVEIRA, A.J. de; CARUSO, J.G.B. Leite: obtenção e qualidade do produto fluido e derivados. Piracicaba: FEALQ, 1996. 80p.

SAS Institute. SAS/STAT user's guide: version 6 . 4.ed. Cary: Statistical Analysis System Institute, 1990. 1022p.

SOMACOUNT 300. Operator's manual. Chaska: Bentley Instruments, 1995. 112p.

Recebido para publicação em 13.05 .99

Aceito para publicação em 26.07.99 